nephron

Practice
Nephron 2016;134:43-49

DOI: $10.1159 / 000444062$
Received: December 16, 2015

Accepted after revision: January 14, 2016 Published online: February 5, 2016

\title{
Estimated Glomerular Filtration Rate: Fit for What Purpose?
}

\author{
David G. Warnock \\ Department of Medicine, University of Alabama at Birmingham, Birmingham, Ala., USA
}

\section{Key Words}

Serum creatinine - Multivariable regression models . eGFR · Cockcroft Gault equation · Relative integrated discrimination improvement than the Cockcroft Gault equation for estimating measured GFR at a single point in time, eGFR does not perform as well as $\mathrm{eCrCl}$ for assessing risk of all-cause mortality over 10-year follow-up intervals.

(c) 2016 S. Karger AG, Basel

\begin{abstract}
There is important nosologic utility in staging chronic kidney disease (CKD) based on estimates of glomerular filtration rate (GFR). These equations have been optimized for estimating GFR at a single point in time. Risk assessment models used for prognosis of specified outcome events have commonly incorporated estimated GFR (eGFR), but the validity of this approach has not been evaluated. The current objective is to evaluate the risk of all-cause mortality over a 10-year follow-up period with multivariable-adjusted Cox regression analysis, comparing CKD stages based on eGFR to CockcroftGault estimated creatinine clearance $(\mathrm{eCrCl})$. There were significant differences between Stage 3A and Stage 3B-5 hazard ratios for all-cause mortality $(p=0.003)$ using eCrCl categories, but not for the same eGFR categories ( $p=0.241$ ). Discrimination analysis showed that a clinically significant difference (relative integrated discrimination improvement $778.6 \% ; p=0.001$ ) was observed between the 2 models for the age strata $\leq 64$. While eGFR is more precise and accurate
\end{abstract}

\section{KARGER}

(C) 2016 S. Karger AG, Basel

E-Mail karger@karger.com

www.karger.com/nef

\section{Introduction}

Chronic kidney disease (CKD) is associated with adverse outcomes, such as incident end-stage renal disease (ESRD), all-cause mortality, hospitalization, and cardiovascular disease [1-6]. Risk prediction models have been developed to estimate individual level risk, but there are well-recognized challenges to developing such models in CKD [7]. There may be complex non-linear [3, 6] or timedependent $[1,2]$ relationships between risk factors and outcomes in CKD. Furthermore, associations with demographics factors may be confounded when estimated glo-

Contribution from the Special Symposium to celebrate the contributions of David G. Warnock, MD to Academic Nephrology, the University of Alabama at Birmingham, Division of Nephrology, November 9, 2015. 
merular filtration rate (eGFR) is included in the models because age, gender and race as well as serum creatinine $(\mathrm{sCr})$ concentration are embedded in the eGFR calculations [8]. Recent papers [9-11] reported that the Cockcroft-Gault estimated creatinine clearance $(\mathrm{eCrCl})$ equation outperformed sCr-based eGFR equations for assessing the long-term risk of all-cause mortality.

The objectives of this inquiry were to calculate the risks of all-cause mortality over 10 years with Cox multiple regression analysis, comparing eGFR to eCrCl categories, and to evaluate the effects of incorporating interactions between age and race and eGFR or eCrCl into the regression models.

\section{Materials and Methods}

The Reasons for Geographic and Racial Differences in Stroke (REGARDS) study cohort included 30,183 black and white individuals 45 years of age and older between January 2003 and October 2007 [12, 13]. Enrollment was all done by mail and telephone: individuals were identified from commercially available lists of residents, and initially contacted by a mail followed by telephone contact. Using a computer-assisted telephone interview, each enrollee provided detailed interview data on an array of measures including demographics, cardiovascular risk factors, cognitive function, general health status, health-related quality of life, lifestyle choices (smoking, alcohol use, physical activity, etc.), access to care, and indices of depression and stress. A brief physical exam including blood pressure measurements, blood and urine samples, anthropometry (height and weight), and an electrocardiogram was conducted in person 3-4 weeks after the telephone interview. Consent was obtained verbally during the telephone interview and later in writing as part of the in-home visit. Additional methodological details are provided elsewhere [12]. The UAB Institutional Review Board approved the protocol and all participants gave written informed consent.

The present analysis excluded participants with missing values for active follow-up status, eGFR, and urine albumin-to-creatinine ratio (ACR). The effect variables included creatinine-based eGFR [14] and $\mathrm{eCrCl}$ [15] (not adjusted for ideal body weight), with categories defined as: $\geq 60 \mathrm{ml} / \mathrm{min} / 1.73 \mathrm{~m}^{2}$ or $\mathrm{ml} / \mathrm{min}$ (reference); $<60$ and $\geq 45 \mathrm{ml} / \mathrm{min} / 1.73 \mathrm{~m}^{2}$ or $\mathrm{ml} / \mathrm{min}$ (category 1 ); and $<45 \mathrm{ml} /$ $\mathrm{min} / 1.73 \mathrm{~m}^{2}$ or $\mathrm{ml} / \mathrm{min}$ (category 2 ). Other categorical covariates included gender, race and urinary ACR stratified at $30 \mathrm{mg} / \mathrm{g}$ (ACR30).

All-cause mortality was ascertained through active follow-up with participants or with personal contacts and online searches of the Social Security Administration's Death Master File http://ssdi. rootsweb.ancestry.com/. Outcomes were censored at the date of death or last recorded follow-up date, updated through March 29, 2013.

Multivariable-adjusted Cox models were used to evaluate hazard ratios (HRs) for all-cause mortality with 10-year follow-up. Participants (267) who progressed to ESRD were not included in the death outcome. The effect variables (eGFR and eCrCl) included a reference category and 2 risk categories, and the covariates were coded as indicator variables with the reference category coded as 0 , and the risk categories coded as 1 or 2 . Interactions with age and race were included in the final models. Relative integrated discrimination improvement (rIDI), with a priori criterion for clinical significance was set at 10\% [16, 17]. STATA (version 14.1, College Park Station, Tex., USA) was used for statistical analysis and graphical support.

\section{Results}

\section{Baseline Characteristics}

Following exclusion of those with missing covariates values, there were included 25,952 participants with 3,822 deaths. Baseline characteristics are shown in table 1. Participants within the reference groups (eGFR $>60 \mathrm{ml} /$ $\mathrm{min} / 1.73 \mathrm{~m}^{2}$ or eCrCl $>60 \mathrm{ml} / \mathrm{min}$ ) were significantly younger than those in risk categories 1 ( $64 \pm 9$ vs. $72 \pm$ 9 years $(\mathrm{p}<0.001)$, and $63 \pm 9$ vs. $74 \pm 8$ years $(\mathrm{p}<0.001))$, or risk categories $2(64 \pm 9$ vs. $73 \pm 9$ years $(\mathrm{p}<0.001)$, and $63 \pm 9$ vs. $78 \pm 8$ years $(\mathrm{p}<0.001))$. Participants in risk category 2 for eCrCl were significantly older than participants in risk category 2 for eGFR (78 \pm 8 vs. $73 \pm$ 9 years $(\mathrm{p}<0.001))$.

\section{Cox Models}

HRs for all-cause mortality associated with the effect variables, and interactions between the effect variables and age and race are shown in table 2. There were timedependent effects (proportional hazard 'violations') and significant interactions between age and race and the effect variable categories. When these interactions were included in the regression models along with urinary ACR30, no significant difference (Wald test) was noticed between the HRs for category 1 and category 2 for eGFR $(\mathrm{p}=0.742)$. Similar results were seen for eGFR-MDRD categories (online suppl. table 1; for all online suppl. material, see www.karger.com/doi/10.1159/000444062): there was no significant difference of any kind between the HRs for category 1 and category 2 for eGFR-MDRD $(\mathrm{p}=0.436)$. In contrast, there was a significant difference between category 1 and 2 for $\mathrm{eCrCl}(\mathrm{p}=0.003$; table 2$)$.

Survivor functions are shown in figure 1 , based on Cox regression models with eGFR or eCrCl categories, demographic factors (age, race, gender) and interactions between the effect variables and age and race. The lack of significant difference between eGFR category 2 and 1 was evident by the overlapping 95\% CIs (fig. 1a), while the significant difference between eCrCl categories 1 and 2 in the multivariable adjusted models (table 2) corresponds to the non-overlapping 95\% CIs in figure 1c. 

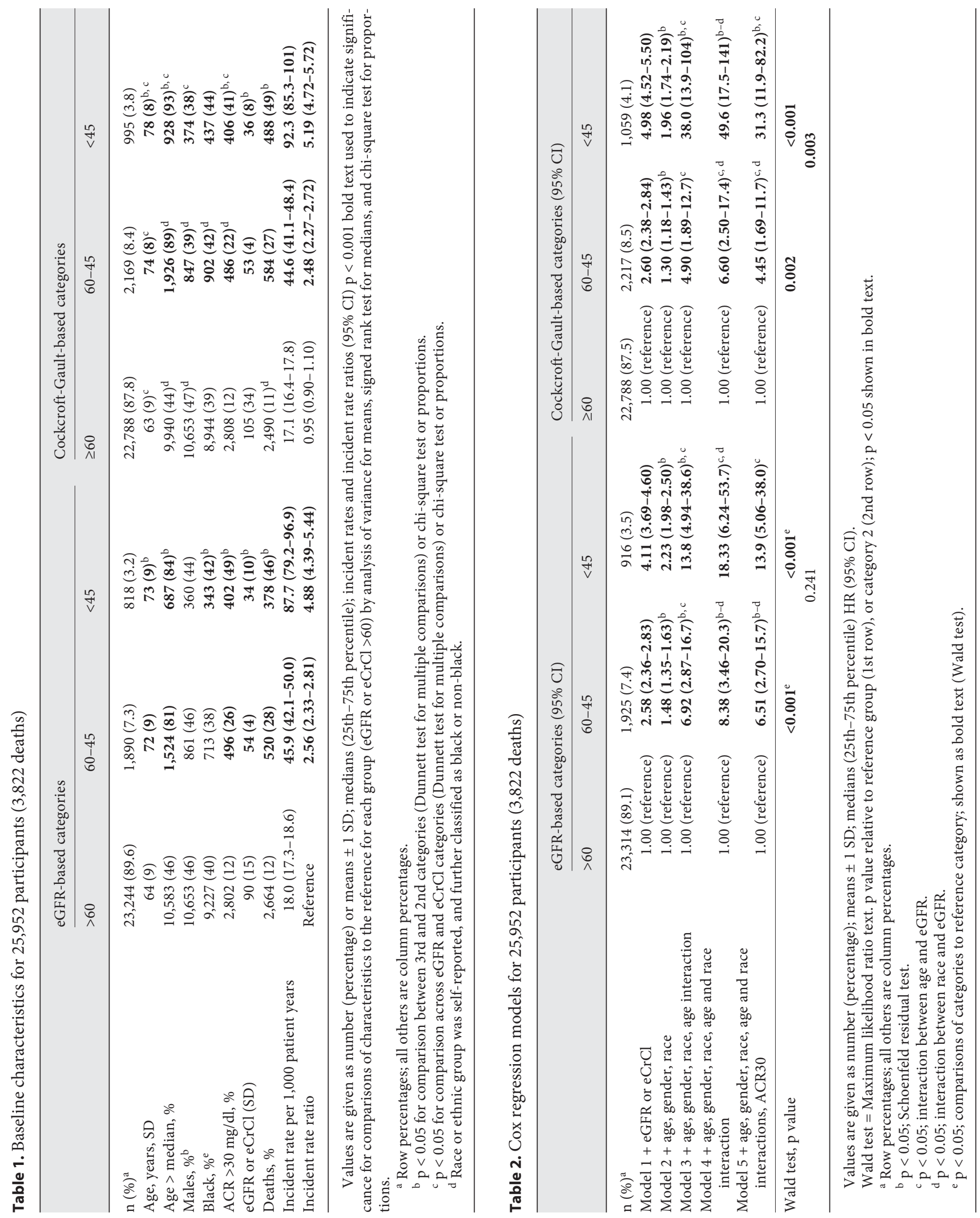


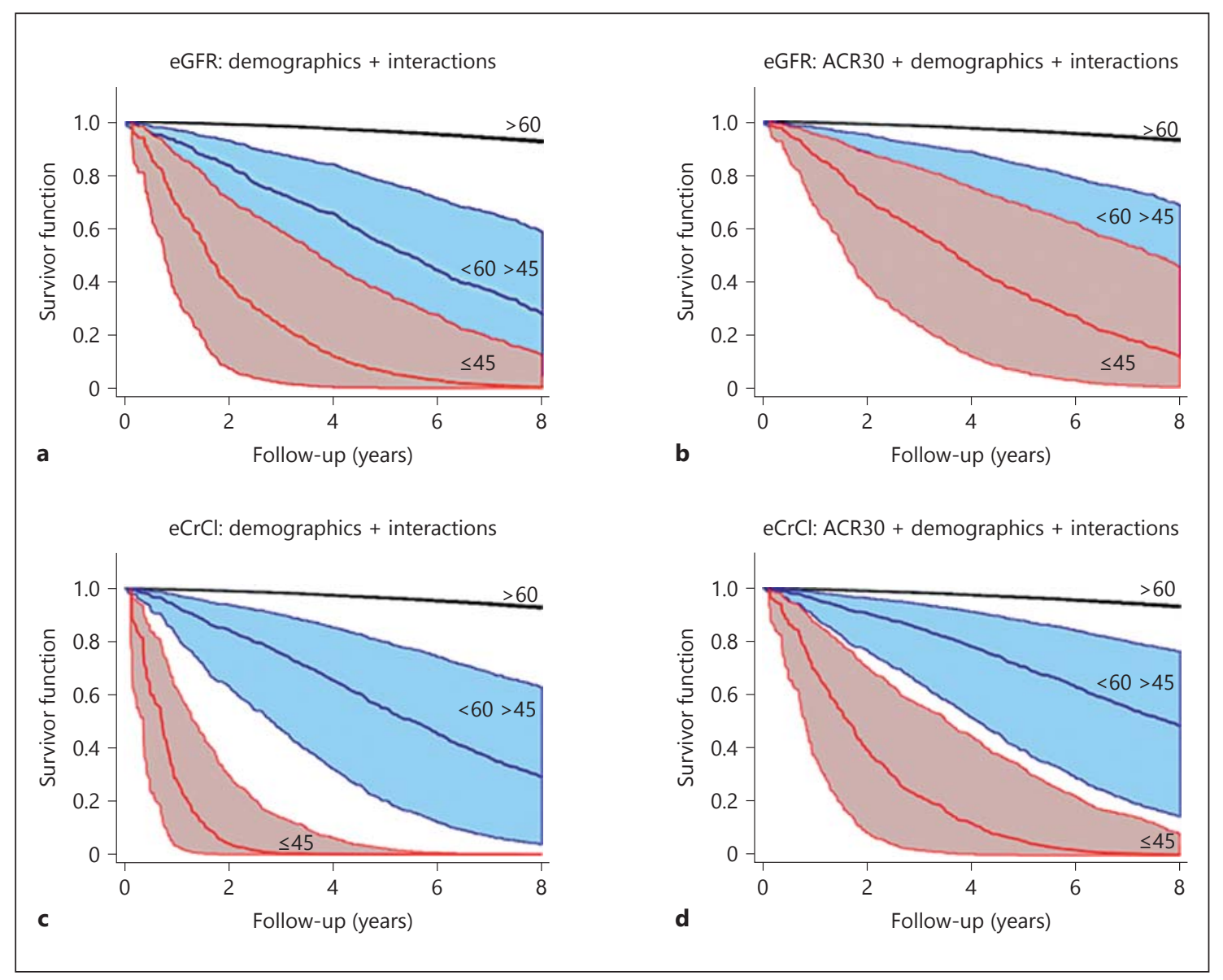

Fig. 1. Survivor functions: eGFR and eCrCl categories. Cox proportional hazard models included eGFR or eCrCl categories $(>60$; $<60$ and $>45 ;<45)$, age, race and gender $(\mathbf{a}, \mathbf{b})$. Urinary ACRs

When ACR30 was added to the regression models, the separation was not improved for the eGFR model (fig. 1c), and continued to be significant for the eCrCl model (fig. 1d).

\section{Discrimination Analysis}

Table 3 shows the results for discrimination analysis between the eGFR and eCrCl categorical Cox models, with stratification at the median age of 64 and by race. No significant discrimination (using rIDI analysis) existed between the Cox models over the entire age range, with rIDI $-0.6 \%(95 \% \mathrm{CI}-1.1$ to $0.1 ; \mathrm{p}=0.077)$. Stratification at the median age of 64 resolved the age interaction with eGFR, and also resulted in significant discrimination between the Cox models. For the age strata $>64$, the rIDI was statistically significant $-1.5 \%$ (95\% CI -2.3 to $-0.7 ; \mathrm{p}<0.001$ ), and favored the eGFR model, but did not reach the a priori criteria of $10 \%$ for clinical signifi- (stratified at $30 \mathrm{mg} / \mathrm{g}$ ) were added to the final model $(\mathbf{c}, \mathbf{d})$. Interactions between age and race and the effect variables were included in all models. cance $[16,17]$. In contrast, for the age strata $\leq 64$, the rIDI was statistically and clinically significant with rIDI 78.6\% (95\% CI 75.0-82.2; $\mathrm{p}<0.001$ ), favoring the eCrCl model. Stratification by race did not produce clinically significant discrimination between the eGFR and eCrCl regression models (table 3 ).

\section{Discussion}

In summary, the current analysis shows that prognostic models for the risk of all-cause mortality are more appropriately based on the Cockcroft Gault eCrCl than the creatinine-based eGFR because the latter model does not clearly separate the risks associated with all-cause mortality associated with Stage 3A and more severe stages of $\mathrm{CKD}$ when an interaction terms are included in the regression models. 
Table 3. Discrimination analysis of Cox models, with stratification at median age (64 years)

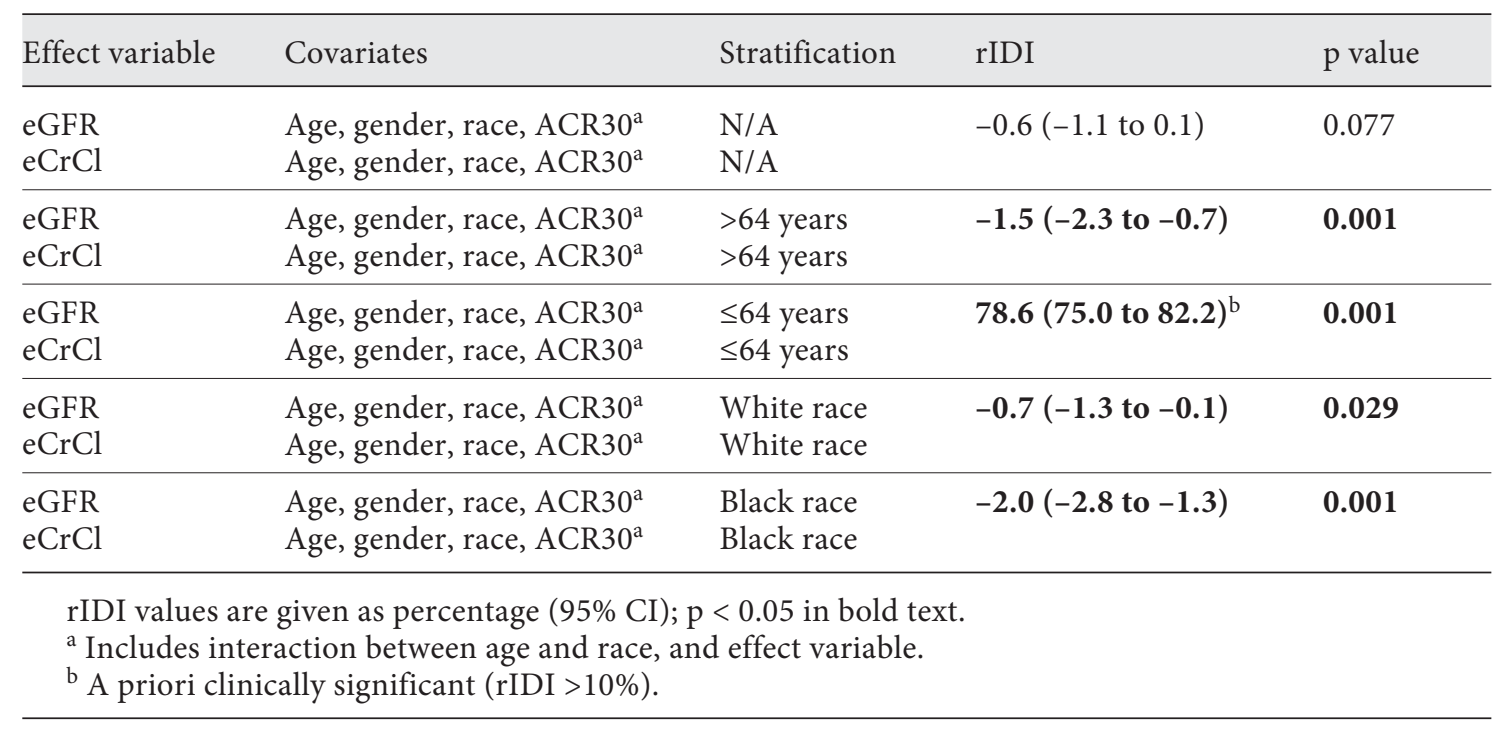

Prevalence estimates for CKD obviously reflect the diagnostic criteria, and there are continuing discussions about the validity of these criteria, especially for elderly subjects $[18,19]$. What is generally accepted is the nosologic utility of CKD staging [20], and the relative reduction of risk for ESRD among elderly patients with CKD $[21,22]$.

The need for accurate and reliable models for predicting the risk of complications of CKD has been long recognized [23]. There may be complex non-linear $[3,6]$ or time-dependent $[1,2]$ relationships between risk factors and outcomes in $\mathrm{CKD}$, but the possibility that the risks for various outcomes may not be constant (e.g. 'proportional') over time has not been fully addressed in prognostic models for patient with CKD. Many of the current risk prediction models of CKD utilize the creatininebased eGFR as the starting point, and also include age, race, and gender even though these factors are explicitly included in the eGFR expression. Furthermore, the current analysis shows a significant interaction between age and between race, the categorical effect variable that has not been previously appreciated. Both the eGFR and $\mathrm{eCrCl}$ variables showed interactions with time, signifying proportional hazard 'violations', which suggests that time-dependent changes in the risks for all-cause mortality may also need to be considered. These sources of timedependent variation are not relevant to estimating measured GFR at a given point in time, for which the creatinine-based eGFR equations were originally developed $[14,15,24]$.

All-Cause Mortality: eGFR and eCrCl
Three recent papers have concluded that the Cockcroft Gault eCrCl equation out performs the creatinine-based eGFR equations for predicting the risk of all-cause mortality in the outpatient $[9,10]$ and inpatient setting [11]. The present analysis is consistent with these previous reports, and provides an interpretation of the cause of the discrepancy that may be explained by the interaction between age and race, and creatinine-based eGFR. As shown in online supplementary table 2, both the CKD-EPI and MDRD eGFR equations include an exponential function of age, whereas eCrCl is a simple linear function of age in the Cockcroft Gault equation. It is possible that the significant interactions between age and the creatininebased eGFR equations may be attributable to these exponential functions of age. 'J-curves' have been previously described for the association between all-cause mortality and eGFR equations $[22,24,25]$, which may also reflect the exponential function of age and the interactions between age and the eGFR functions. A 'J-curve' phenomenon is not seen with the Cockcroft Gault eCrCl function (data not shown).

This study has several limitations that need to be acknowledged. Laboratory assessments included single determinations at baseline. Because of the random measurement error associated with the use of a single baseline measurement, misclassification could bias our results toward the null. Therefore, the reported estimates of the associations between the effect variables and all-cause mortality are likely to be conservative. Additional assessments would be desirable, especially to evaluate risks that 
vary over time. The number of participants with moderate to severe CKD was limited in the REGARDS cohort, necessitating combing Stage 3B, 4 and 5 into a single category. The relationship between CKD stage and mortality may be unique to the REGARDS study population and/or the current analysis; replication of this approach with other data sets would be most welcome.

The eGFR expression is more precise and accurate than the Cockcroft Gault equation for estimating measured GFR at a given point in time [15], and is fit for that specific purpose. However, eGFR does not perform as well as eCrCl in prognostic models for assessing the risk of all-cause mortality with 10 years follow-up, comprising other recent reports [9-11]. Discrimination analysis suggests that the major differences between eGFR and eCrCl categories were observed for the age strata $\leq 64$ years. Future work will evaluate the performance of eGFR and $\mathrm{eCrCl}$ as continuous variables, as well as for other outcome measures, including competing risks between various outcomes for patients with CKD. Further development of prognostic models in CKD is certainly worth- while, but different outcomes may need different approaches, and the relevant time interval for risk prediction needs to be specified.

\section{Acknowledgments}

The support of the UAB/UCSD O'Brien Center for Kidney Research (P30 DK079337) is acknowledged. Biostatistical assistance from Kunihiro Matsushita, MD, PhD and Ying Ying Sang, MS of the CKD Prognosis Consortium, and the Stata Technical Services group is acknowledged.

\section{Disclosure Statement}

The author has no conflicts of interest to declare relevant to this work.

\section{Statement of Ethics}

The study was approved by the UAB Institutional Review Board and all participants gave written informed consent.

\section{References}

1 Go AS, Chertow GM, Fan D, McCulloch CE, Hsu CY: Chronic kidney disease and the risks of death, cardiovascular events, and hospitalization. N Engl J Med 2004;351:1296-1305.

-2 Warnock DG, Muntner P, McCullough PA, Zhang X, McClure LA, Zakai N, Cushman M, Newsome BB, Kewalramani R, Steffes MW, Howard G, McClellan WM REGARDS Investigators: Kidney function, albuminuria, and all-cause mortality in the REGARDS (reasons for geographic and racial differences in stroke) study. Am J Kidney Dis 2010;56:861871.

-3 Chronic Kidney Disease Prognosis Consortium, Matsushita K, van der Velde M, Astor BC, Woodward M, Levey AS, de Jong PE, Coresh J, Gansevoort RT: Association of estimated glomerular filtration rate and albuminuria with all-cause and cardiovascular mortality in general population cohorts: a collaborative meta-analysis. Lancet 2010;375: 2073-2081.

4 van der Velde M, Matsushita K, Coresh J, Astor BC, Woodward M, Levey A, de Jong P, Gansevoort RT; Chronic Kidney Disease Prognosis Consortium, van der Velde M, Matsushita K, Coresh J, Astor BC, Woodward M, Levey AS, de Jong PE, Gansevoort RT, Levey A, El-Nahas M, Eckardt KU, Kasiske BL, Ninomiya T, Chalmers J, Macmahon S, Tonelli M, Hemmelgarn B, Sacks F, Curhan G, Collins AJ, Li S, Chen SC, Hawaii Cohort KP, Lee BJ, Ishani A, Neaton J, Svendsen K,
Mann JF, Yusuf S, Teo KK, Gao P, Nelson RG, Knowler WC, Bilo HJ, Joosten H, Kleefstra N, Groenier KH, Auguste P, Veldhuis K, Wang Y, Camarata L, Thomas B, Manley T: Lower estimated glomerular filtration rate and higher albuminuria are associated with all-cause and cardiovascular mortality. A collaborative meta-analysis of high-risk population cohorts. Kidney Int 2011;79:1341-1352.

5 Gansevoort RT, Matsushita K, van der Velde M, Astor BC, Woodward M, Levey AS, de Jong PE, Coresh J; Chronic Kidney Disease Prognosis Consortium: Lower estimated GFR and higher albuminuria are associated with adverse kidney outcomes. A collaborative meta-analysis of general and high-risk population cohorts. Kidney Int 2011;80:93104.

-6 Matsushita K, Mahmoodi BK, Woodward M, Emberson JR, Jafar TH, Jee SH, Polkinghorne KR, Shankar A, Smith DH, Tonelli M, Warnock DG, Wen CP, Coresh J, Gansevoort RT, Hemmelgarn BR, Levey AS; Chronic Kidney Disease Prognosis Consortium: Comparison of risk prediction using the CKD-EPI equation and the MDRD study equation for estimated glomerular filtration rate. JAMA 2012; 307:1941-1951.

7 Grams ME, Coresh J: Assessing risk in chronic kidney disease: a methodologic review. Nature Rev Neph 2013;9:18-25.

8 Hsu CY, Cummings SR, McCulloch CE, Chertow GM: Bone mineral density is not di- minished by mild to moderate chronic renal insufficiency. Kidney Int 2002;61:1814-1820.

$\checkmark 9$ Pizzarelli F, Lauretani F, Bandinelli S, Windham GB, Corsi AM, Giannelli SV, Ferrucci L, Guralnik JM: Predictivity of survival according to different equations for estimating renal function in community-dwelling elderly subjects. Nephrol Dial Transplant 2009;24:11971205.

10 Weidmann ZM, Breidthardt T, Twerenbold R, Züsli C, Nowak A, von Eckardstein A, Erne P, Rentsch K, de Oliveira MT Jr, Gualandro D, Maeder MT, Rubini Gimenez M, Pershyna K, Stallone F, Haas L, Jaeger C, Wildi K, Puelacher $\mathrm{C}$, Honegger $\mathrm{U}$, Wagener M, Wittmer S, Schumacher C, Krivoshei L, Hillinger P, Osswald S, Mueller C: Prediction of mortality using quantification of renal function in acute heart failure. Int J Cardiol 2015;201:650-657.

11 Parsh J, Seth M, Aronow H, Dixon S, Heung M, Mehran R, Gurm HS: Choice of estimated glomerular filtration rate equation impacts drug-dosing recommendations and risk stratification in patients with chronic kidney disease undergoing percutaneous coronary interventions. J Am Coll Cardiol 2015;65:27142723.

12 Howard VJ, Cushman M, Pulley L, Gomez CR, Go RC, Prineas RJ, Graham A, Moy CS, Howard G: The reasons for geographic and racial differences in stroke study: objectives and design. Neuroepidemiology 2005;25: 135-143. 
13 Howard VJ, Kleindorfer DO, Judd SE, McClure LA, Safford MM, Rhodes JD, Cushman M, Moy CS, Soliman EZ, Kissela BM, Howard G: Disparities in stroke incidence contributing to disparities in stroke mortality. Ann Neurol 2011;69:619-627.

14 Inker LA, Schmid CH, Tighiouart H, Eckfeldt JH, Feldman HI, Greene T, Kusek JW, Manzi J, Van Lente F, Zhang YL, Coresh J, Levey AS; CKD-EPI Investigators: Estimating glomerular filtration rate from serum creatinine and cystatin C. N Engl J Med 2012;367:20-29.

15 Stevens LA, Nolin TD, Richardson MM, Feldman HI, Lewis JB, Rodby R, Townsend R, Okparavero A, Zhang YL, Schmid CH, Levey AS; Chronic Kidney Disease Epidemiology Collaboration: Comparison of drug dosing recommendations based on measured GFR and kidney function estimating equations. Am J Kidney Dis 2009;54:33-42.

16 Pencina MJ, D’Agostino RB Sr, Steyerberg EW: Extensions of net reclassification improvement calculations to measure usefulness of new biomarkers. Stat Med 2011;30:11-21.
17 Pencina MJ, D’Agostino RB, Pencina KM, Janssens AC, Greenland P: Interpreting incremental value of markers added to risk prediction models. Am J Epidemiol 2012;176:473481.

18 Glassock R, Delanaye P, El Nahas M: An agecalibrated classification of chronic kidney disease. JAMA 2015;314:559-560.

19 Levey AS, Inker LA, Coresh J: Chronic kidney disease in older people. JAMA 2015;314:557558.

20 KDOQI: KDOQI Clinical practice guidelines and clinical practice recommendations for $\mathrm{di}$ abetes and chronic kidney disease. Am J Kidney Dis 2007;49(2 suppl 2):S12-S154.

21 Hallan SI, Orth SR: The conundrum of chronic kidney disease classification and end-stage renal risk prediction in the elderly - what is the right approach? Nephron Clin Pract 2010; 116:c307-c316.

22 Hallan SI, Matsushita K, Sang Y, Mahmoodi BK, Black C, Ishani A, Kleefstra N, Naimark D, Roderick P, Tonelli M, Wetzels JF, Astor BC, Gansevoort RT, Levin A, Wen CP, Coresh
J; Chronic Kidney Disease Prognosis Consortium: Age and association of kidney measures with mortality and end-stage renal disease. JAMA 2012;308:2349-2360.

23 Taal MW, Brenner BM: Predicting initiation and progression of chronic kidney disease: developing renal risk scores. Kidney Int 2006; 70:1694-1705

24 Stevens LA, Li S, Kurella Tamura M, Chen SC, Vassalotti JA, Norris KC, Whaley-Connell AT, Bakris GL, McCullough PA: Comparison of the CKD epidemiology collaboration (CKD-EPI) and modification of diet in renal disease (MDRD) study equations: risk factors for and complications of CKD and mortality in the kidney early evaluation program (KEEP). Am J Kidney Dis 2011;57(3 suppl 2):S9-S16.

25 Shastri S, Katz R, Rifkin DE, Fried LF, Odden MC, Peralta CA, Chonchol M, Siscovick D, Shlipak MG, Newman AB, Sarnak MJ: Kidney function and mortality in octogenarians: cardiovascular health study all stars. J Am Geriatr Soc 2012;60:1201-1207. 